\title{
Driving system of university mathematics practice teaching system I:
}

\section{view of teacher}

\author{
Xiaobo Liü, a \\ ${ }^{1}$ School of information engineering, Nanjing Xiaozhuang University, Nanjing, China \\ a4487758@qq.com
}

Keywords: university mathematics, practice teaching system, driving system; the view of teacher.

\begin{abstract}
If the university mathematics teaching was divided into theoretical teaching and practical teaching, so these two different types of teaching not only perform differences on teaching content and ways, but also change the way of thinking. It decided these two types must have essential differences in view of teacher, curriculum, learning, knowledge and other aspects.
\end{abstract}

\section{Introduction}

If the university mathematics teaching was divided into theoretical teaching and practical teaching, so these two different types of teaching not only perform differences on teaching content and ways, but also change the way of thinking. As Thomas Kuhn said, "the new paradigm from the old paradigm out was far from being a process of accumulation, which is one could not modify or extend through the old paradigm of the process. Rather, it was a reconstruction process in the field of the study on a new basis, this reconstruction had changed some most basic theoretical generalization in the research field, also changed the method and application of many paradigms in this research field. ${ }^{[1]}$ This meant that the theoretical teaching and practical teaching are two different paradigms, and it decided these two types must had essential differences in view of teacher, curriculum, learning, knowledge and other aspects.

Under the influence of the traditional teaching theory as the representative of Comenius and Herbart, the schools of China formed the characteristics of taking teacher, textbook and classroom as center in the long process of development of teaching. It emphasized to establish a complete and applicable theory system by exploring the law of teaching objectives, teaching tasks, teaching content and teaching process. The teaching theory existed by the form of assured and eternal truth, pursued the identity and certainty of teaching, and neglected the richness and diversity of teaching, this rigid teaching theory did not allow any change and transcendence. Teaching was regarded as a one-way transmission of information process however, but not interactive process. In the classroom teaching, teachers teaching knowledge around the teaching materials had become the main way of teaching, the teacher was the controller and initiator of teaching activities, teachers played an important role on the teaching content and the reaction of students. The main task of teaching was choosing a teaching tool to screen, filter and process teaching information, and transmissed them to the students. Some teachers had some errors to mathematics teaching practice in the thought, such as function in textbooks, the application of derivative, for the plane area by means of the integral and the volume of rotating type, we are very clear, but did not consider what is really useful, and which is not used at all. The teacher derived the symbols from mathematical symbols in the 
teaching practice of mathematics, which made students thought math was "symbol", and led mathematics teaching from the reality. The student-centered activities and the application consciousness for the purpose of the classroom became the stage what the teacher instilled the mathematical definition, theory and symbol system constantly, students' training of application consciousness and creative thinking became a formidable deduction and repetition of the formal training. Mathematics teaching should be exposed how mathematics was abstracted from the practical background material as far as possible, and how to apply to the whole process of solving practical problems. We just focus on understanding, proving and deriving the teaching of mathematical concept and theorem, but ignored its application and the ideological education of "integrating mathematics with reality".

The students were regarded as the object to receive information. In this view of teaching, thinking and activities of the students' rights were deprived intangibly, personality and talent development were repressed. The way of students' learning knowledge was relatively simple, most mathematical knowledge relied on textbooks, lack the process of students' independent exploration and cooperative learning, and lack reflection and adjustment of learning knowledge. In classroom, teachers did not pay enough attention to cultivate students' learning emotion, and arouse their learning enthusiasm; put undue emphasis on teaching knowledge, and ignored the exploration of the process; gave the concept directly, and then verified and interpreted the concept, the phenomenon was relatively common. This kind of classroom learning process was not complete, because the students were lack of the process of exploring and discovering knowledge, their interests of knowledge could not be by learning, and the spirit of innovation and application of consciousness could not be effectively cultivated.

Mathematics teaching should be possible to restore the original appearance of knowledge generation, development, it should be from the practice, and used to solve the practical problems. And now we have some mathematics teaching practice in draw further apart, it paid one-sided emphasis on the logical reasoning process of knowledge, but ignored its application, and ignored integrating the knowledge with reality. In comparison, under the practice oriented teaching concept, teachers knowledge monopoly was broken, the students obtain the learning initiative through their own initiative construction, they became the creator and disseminator of knowledge, every student is the one and only the individual, their different experience and life background determined the knowledge building was different. And teachers played the role of facilitator and coordinator in the process of construction activities of students actively.

\section{Change the teaching idea and strengthen the consciousness of practice}

Mathematics practice consciousness is formed by the learning content of perception and specific mathematical activities experience. Therefore, in the process of teaching, teachers can introduce mathematical knowledge through abundant examples, guiding students to apply mathematical knowledge to solve practical problems, to experience the process of exploring and solving the problems, it let students realize mathematical existence in real life, and can be widely used in the real world, that is to say as long as the students would integrate mathematical knowledge with production and life, they could truly appreciate the value of mathematics application, and enhance the consciousness of mathematics application. But in fact, many teachers immersed in logical derivation and computing skills in the teaching, they did not pay attention to the development of students' application consciousness. On the other hand, most mathematics teachers did not have communication with professional teachers, the teacher's mathematics application consciousness is 
not strong, which caused teaching content contributed little to the learning of professional course. Therefore, mathematics teachers should actively improve their own quality, take the initiative to understand the application of mathematics in practice and develop using the mathematical way of thinking in daily life to observe the problem, improve their consciousness of mathematics application. At the same time, they should change teaching idea, to reform the teaching methods, and permeate mathematical education thought with imparting knowledge, adding some practical problems to enable students to gradually form the awareness of applying mathematical knowledge and methods to solve practical problems.

\section{Create professional context, and active classroom teaching}

In mathematics classroom teaching of different professional college, it must work closely with the production, life and students' professional practice. It should take students as center and pay attention to the relationship between students level with occupation ability. Through the creation of occupation situation, it activate classroom teaching, so as to achieve the goal of cultivating students' application ability.

Example: in a recruitment meeting, two garden companies including A and B are willing to hire you. They were out of the contract is ten years, the company A promised monthly salary of the first year is 1500 yuan, later the monthly salary of every year increase 230 yuan than the monthly salary of last year, the company B promised monthly salary of the first year is 2000 yuan, later the monthly salary of every year increase $5 \%$ than the monthly salary of last year. If taking more total wage income as a standard, which company do you choose to sign? Signing the same job for ten years, and working in different companies, how much is your salary income?

Through the example which is in close contact with the actual life of students, it let students feel mathematics not only have theory, but also have the practice, mathematics is from the reality, in reality, and the mathematics is around us.

\section{Carry out mathematical modeling activities, and cultivate mathematics application awareness}

Mathematical modeling is the process of solving practical problems using mathematical thought, method and knowledge, and a bridge between mathematics and practical problems. Through mathematical modeling, mathematical knowledge could be reasonably applied to the practice, it could let students experience application value of mathematics, effectively enhance the students to use mathematical knowledge, enable students to understand the process of mathematics knowledge, improve the ability of analyzing and solving practical problems with mathematical knowledge.

Choose the material with experience and background for mathematical modeling. In mathematical modeling, the problem is the key. The problem of mathematical modeling is various, it should come from the daily life of the students, the real world, other disciplines and other aspects. It is good for students to experience application value of mathematics, thus promoting the formation of mathematics application consciousness. Teachers in the teaching process, should focus on the analysis of the numerical relationship, to help students realize the mathematic problem, there are many mathematical models of mathematics teaching materials, and teachers should fully tap the practical problems in teaching materials, and select the suitable type of basic modeling problem.

For example: a store launch a series of promotions, some commodities hit $15 \%$ off, some send coupons with a certain amount, such as send 40 with 200. By observing, the same brand of the same commodities are the same as in the original price of each shop. Which shop is cost-effective? 
Teachers guide students to analyze and establish a simple mathematical model to solve.

Set the store with playing $15 \%$ off for A, the shop with sending 40 with 200 for B. Assuming that the planned consumption $x$ yuan, the actual consumption in A store is $y_{1}$ yuan, the actual consumption in the B store is $y_{2}$ yuan, you can get a functional relationship:

$$
\begin{aligned}
& y_{1}=0.85 x \\
& y_{2}=\left\{\begin{array}{c}
x, x \leq 200 \\
x-40,200 \leq x \leq 400 \\
\cdots \\
x-40 n, 200 n \leq x \leq 200(n+1)
\end{array}\right.
\end{aligned}
$$

When $x \leq 200, y_{1} \leq y_{2}$, you should go into the store A.

When $200 \leq x \leq 400$ 时, $y_{2}-y_{1}=0.15 x-40$

When $x<266.67, y_{2} \leq y_{1}$

When $x=266.67, y_{2}=y_{1}$

When $x>266.67, y_{2}>y_{1}$

So, when $200 \leq x<266.67$, you should go into the store B; when $x=266.67$,you should go into the store A or B; when $266.67 \leq x<400$, you should go into the store A.

It can be seen what store you should go have relationship with the amount of the planned consumption, only to determine the amount of planned consumption first, you could be in order to decide which shop to go more cost-effective.

Establish a mathematical model, abstract the actual problem as a mathematical problem. Abstracting mathematical model from the practical problems is the key application of mathematics. Teachers by introducing the open or exploratory examples which have practical background close to real life, production and other disciplines in the teaching practice, to guide the students to read issues which are closely related to real life in books, and actively participate in social practice, to understand the mathematics application in life, production and science and technology. It described, understood the practical problems with mathematical language, knowledge and thinking method, abstracted the practical problems into mathematical problems.

Example: an export company’s monthly sales of $\$ 1$ million, the average profit is $10 \%$ of sales volume. The rate of change of monthly sales is similar to the growth curve $1000000 e^{0.02 t}$ of the company during the period of advertising ( $\mathrm{t}$ is on month). The company now needs to decide whether to have a total cost of $\$ 130$ thousand for the campaign, as usual, for the advertising campaign more than $\$ 100$ thousand, if the profit of added sales volume is more than $10 \%$ of advertising investment, the company decided to advertise. How the company should do the advertising customary? 
First, it should let students understand what is required to produce, that is the new sales profit is more than $10 \%$ of advertising investment, if exceeding, and it should decide to do. Second, the title is broken down into the following problems: the total annual sales, added sales, the profits of added sales and actual profits generated by advertising. After the students find out these problems, it is not difficult to establish a mathematical model.

Inspect seriously, and learn to use the actual test results. Mathematical modeling is the process of solving practical problems using mathematical thought, method and knowledge, the solution must accord with the objective reality, and guide the practice. The different modeling methods decided the different results, so we need to test the model, this is an important part of the mathematical modeling. In the inspection process of model, the teachers should guide the students to participate in social practice, experience the relationship between mathematics and life practice, and penetrate the thinking of applying mathematics to reality.

Strengthen the practice, and improve the application of consciousness. It need students choose the most appropriate mathematical tools, establish mathematical model, collect data, analyze and calculate through the analysis and simplification of the actual problem, and test the accuracy and reliability of the model, it is an effective means for the development of students' innovation consciousness and practical ability, for example, in the teaching of the function, teachers should encourage students to find the situation and examples of piecewise function for themselves. In learning the correlation variables in statistics, teachers should guide the students how to use regression analysis to distribution curve. It let students experience mathematics value and role in solving practical problems, experience the relationship between mathematics and daily life, experience the process of solving practical problems using knowledge and methods comprehensively.

\section{Setup the mathematics experiment class, and cultivate the ability of application}

The mathematics experiment is the process of putting forward the reasonable assumptions according to the characteristics and requirements of practical problems and after the correct analysis, abstracting the actual problem as mathematical problems, establishing a mathematical model with mathematical knowledge, and integrating the actual problem, mathematical model and computer with the aid of the computer results.

Compared with the traditional mathematics curriculum, mathematics experiment course focus more on transforming the practical problems into mathematical problems, more focus on the cultivation of innovative consciousness and scientific computing ability. Therefore, mathematics experiment course is an important link of strengthening the practice and cultivating students' application ability.

The mathematics experiment can be taught by using computer and instructing, it can be divided into three steps. The first step, teachers explained the specific background, calculation method and numerical modeling method of issues in the experiment, including simplification of the related conditions, separation and selection of variable factors, establishing the relationship between variables and the mathematical method, and the theory of solving the mathematical model and computer instructions. The second step, the students discussed by groups, and established the mathematical model. The third step, students operated by computers, obtained the analytical and numerical solutions by using mathematical software, and wrote the experiment report. 


\section{Acknowledgement}

The teaching project of Nanjing Xiaozhuang University: Research on "university mathematics" practical teaching under the goal of training applied talents stage result. The project of reforming and developing significant and important problems during The 13th Five-year of Nanjing Xiaozhuang University: Research on "university mathematics" practical teaching under the goal of training applied talents in local undergraduate colleges and universities (2016XZGJ07) stage result. The sub-project of the Twelfth Five-year plan key project "Research on teachers' professional development" of National Teacher Research Fund of China: Research on "university mathematics" practical teaching (GJS1523125) stage result.

\section{Reference}

[1] Thomas Kuhn, Structure of Scientific Revolution, Peking University press, p. 78, 2003. 